\title{
AN INTEGRATED APPROACH, APPLICATIONS AND ENHANCEMENT OF NANOFLUIDS IN HEAT TRANSFER
}

\author{
Raghav Dosi $i^{*}$, Pawan Sharma² \\ ${ }^{1}$ Research Scholar Vivekananda Institute of Technology (East), Jaipur, India \\ 2Vivekananda Institute of Technology (East), Jaipur, India \\ E-mail: shonidosik@gmail.com
}

\begin{abstract}
-:
This paper presents a procedure for preparing a nanofluid, which is a suspension consisting of nanophase powders and a base liquid, by means of the procedure, some sample of nanofluids are prepared. The theoretical study of the thermal conductivity of nanofluids is introduced. A theoretical model is proposed to describe heat transfer performance of the nanofluid regarding its radioactive properties in Direct Absorption solar collector. This paper also consists of usance of nanofluids through application and provokes the funding for its research purpose for the development of nanotechnology and the challenges in front of us for the domestic use of nanofluids in heat transfer. It also comprises of the parameters and materials for nanoparticles and base fluids for thermal conductivity enhancements.
\end{abstract}

Keywords: Nanofluid, Enhancement, Heat transfer, Radioactive, Nanoparticle, basefluids.

\section{INTRODUCTION}

Nanofluid is a name, which is a combination of nanoparticles and basefluids. Nanoparticles are just a particles, those are in size of nano. Nanofluids are prepared by inserting nanoparticles in the fluid suitable for this so, the fluid used are called as Basefluids. For preparation there should be a proper composition of nanoparticle and basefluid with suitable ambient conditions otherwise optimization is not possible. The materials must have good thermal conductivity for the enhancement.

The generation of sustainable energy is an important concern facing by our society today. Solar energy is only energy available in vast amount on earth. Proper utilization of solar energy can be done by the use of nanofluids through Direct Absorption Solar Collector. There are many sources of energy on earth but with major drawbacks. For e.g. Fossils fuels viz. petroleum, coal, natural oil, etc. but they are consists of air pollution which is always an issue for governments, environmentalists, investors and researchers. Nanofluids are capable of controlling heat by transfer and storage in very finite manner with its useful properties of thermal conductivity. For the transformation of solar radiation energy into internal energy, solar thermal collectors play a vital role as heat exchangers.
An innovative way of improving the thermal conductivities of fluids is to suspend small solid particles in the fluids. Various types of powders such as metallic, non-metallic and polymeric particles can be added into fluids to form slurries. The thermal conductivities of fluids with suspended particles are expected to be higher than that of common fluids. There were tests carried out for industrial application in which the effect of particle volumetric loading, size, and flow rate on the slurry pressure drop and heat transfer behavior was investigated but still can't considered as developed. In conventional cases, the suspended particles are of Im or even $\mathrm{mm}$ dimensions. Such large particles may cause some severe problems such as abrasion and clogging. Therefore, this suspension oflarge particle has little practical application in heat transfer enhancement.

\section{LITERATURE REVIEW}

Application of nanoparticles provides an effective way of improving heat transfer characteristics of fluids (Eastman et. al.1997). Particles having size of $<100 \mathrm{~nm}$ in diameter exhibit properties different from those of conventional solids. This difference made nanofluids as a huge heat controlling source.

Some researchers tried to suspend nanoparticles into fluids to form high effective heat transfer fluids. Choi (1995) is the first who used the term Nanofluids to refer to the fluids with suspended nanoparticles. Some preliminary experimental 
results showed that increase in thermal conductivity of approximately $60 \%$ can be obtained for the nanofluid consisting of water and 5 vol\% $\mathrm{CuO}$ nanoparticles. By suspending nanophase particles in heating or cooling fluids, the heat transfer performance of the fluid can be significantly improved.

The current applications in mini devices call for special fluids to transfer the heat more efficiently. This trend in nanotechnology provided an opportunity to produce nanomaterials with below 50nm size. Choi (1995) conceived the concept of nanofluids by making of these particle size in order of $1-100 \mathrm{~nm}$. Nanofluids belongs to a step of nanotechnology in heat transfer produced by dispersing conventional nanometer sized particles in fluids along with additives to increase the thermal stability . As compared with conventional particles of mili or micro meter dimensions, nanofluids show better stability, high thermal conductivity with avoidable pressure drop.

The unique properties of nanofluids viz. large surface area to volume ratio, lower Kinetic energy which can be highly utilized in various applications. Eastman (1995) reported that an increase in thermal conductivity was observed by adding only $0-3 \% \mathrm{Cu}$ particles with $10 \mathrm{~nm}$ diameter in base fluid ethylene glycol. Now fabrication of microscale devices such as microchannel heat exchanger and micro pumps can be improved by engineers in variety of applications.

\section{PREPARATION OF NANOFLUIDS}

Nanofluids made from metals, oxides, carbides and carbon nano-tubes can be suspended in heat transfer fluids, such as water, ethyleneglycol, hydrocarbons, and fluorocarbons with the addition of stabilizing agents. The preparation is the initial step for the enhancement of conductivity. Nanoparticles can be produced from several processes, such as gas condensation, mechanical insertion or chemical precipitation.

The particles can be produced under cleaner conditions and their surface can be protected from undesirable coatings during the gas condensation process. The main drawback of this method is that the particles made by this technique produce some agglomeration and its unsuitability to make pure metallic nanopowders. The formation of agglomeration can be controlled to some extent by using a direct evaporation condensation method. This method provides close control over particle size and produces particles for stable nanofluids without surfactants or electrostatic stabilizers, but has the disadvantage of oxidation of pure metals and low vapour pressure fluids.
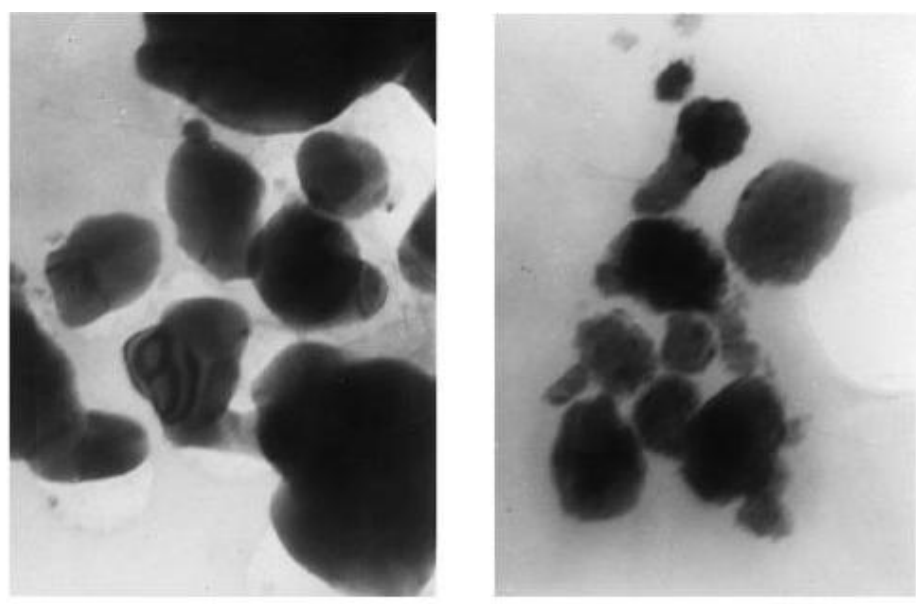

Fig.1: TEM micrographs of nanoCu particles \pm transformer oil at $\mathrm{pH}$ 6.3

\section{EXTRAORDINARY PERFORMANCE OF NANOFLUIDS IN HEAT TRANSFER}

The main reasons behind the extraordinary performance of nanofluids in heat transfer are listed as follows:

1. The suspension of nanoparticles in the basefluids increases the surface area and the heat capacity of the fluid.

2. The suspended nanoparticles increase the effective heat transfer capacity of the fluid.

3. The collision and encounter among particles, fluid and the flow causes passage surface intensified.

4. The mixing fluctuation and turbulence of the fluid are intensified.

5. The transverse temperature gradient of the fluid flattens by the dispersion of nanoparticles in basefluids.

\section{RADIOACTIVE PROPERTIES OF COMPONENTS OF NANOFLUIDS}

\section{A. Nanoparticles}

The nanoparticles are provided in a very small size i.e. nanoand the volume fraction is only a small portion of the base fluid. So, the scattering effect of nanoparticles in nanofluid can be considered to be independent. The simple proportionality to the number of particles holds only if the radiation to each particle is exposed which is essentially the light of the original beam. 
Actually, each particle is also exposed to light scattered by the other particles, whereas the light of the original beam may have suffered extinction by other particles. In the study of nanofluids, the nanoparticles influence the nature of absorption as well as scattering.

\section{B. Basefluids}

In order to fully understand the effects of suspending nanoparticles with a basefluid, the complete optical properties of the base fluid are required. The bulk receiver is the fluid medium; therefore, the radiative properties of the fluid are effective on the efficiency of a volumetric design. An ideal fluid for a volumetric application would be completely transparent to the incoming solar radiation.Basefluids normally used Direct solar collectors as water heater which is non toxic and best for absorbing solar energy.

\section{MATERIALS FOR NANOPARTICLES AND BASEFLUIDS}

The following are the Materials for Nanoparticles and Basefluids:

1. Nanoparticle materials include:

- Oxide ceramics - Al2O3, CuO

- Metal carbides - SiC

- Nitrides - AIN, SiN

- Metals - Al, Cu

- Nonmetals - Graphite, carbon nanotubes

- Layered - Al + Al2O3, Cu + C

- Functionalized nanoparticles

2. Basefluids include:

- Water,

- Ehtylene or triethylene glycols and other coolants,

- Oil and other lubricants,

- Bio-fluids,

- Polymeric solutions,

- Other common fluids.

\section{THERMAL CONDUCTIVITY OF NANOFLUID MATERIALS}

For the optimum use of nanofluids, the combination of nanoparticles and basefluids should be suitable according to the particular application. There are some materials for both the components, suggested as below, with this the number of combination are possible results the production of number of nanofluids for the application.

Error! Objects cannot be created from editing field codes. Figure 1 Thermal conductivity of materials

Error! Objects cannot be created from editing field codes.

Figure 2 Thermal conductivity parameters

\section{VIII.HEAT CONDUCTION MECHANISMS IN NANOFLUIDS}

The scientists named as Keblinski presented four possible mechanisms in nanofluids which may contribute to thermal conduction:

1. Heat conduction by Brownian motion of nano sized particles,

2. By Liquid layering at the liquid-particle interface,

3. Due to Ballistic nature of heat transport in nanoparticles, and

4. Clustering of nanoparticles in nanofluids.

The Brownian motion of nanoparticles is too steady to directly transfer heat through nanofluids; however, it could have an indirect role to produce convection like micro ambient conditions around the nanoparticles and particle clustering to increase the heat transfer. This mechanism works well only when the particle clustering has both the positive and negative effects of thermal conductivity which can be controlled by proper composition.

\section{NANOFLUIDS IN SOLAR ENERGY}

Solar energy is a very large, inexhaustible and clean source of energy. The power from sun intercepted by earth is approximately $1.8 \times 10^{11} \mathrm{MW}$ which is many thousands of times larger than the present consumption rate on the earth of all energy sources. Thus, the solar energy has the potential of supplying a large portion of the present and future energy requirements of society. Non-concentrating type of collectors are limited to household water heating systems.

Direct Absorption Collector 
Solar water heating technologies are widespread and contribute significantly to hot water production in several areas. Solar collectors exhibit several applications, such as limitations on incident flux density, relatively high losses, and corrosion effect. In order to overcome these drawbacks, the idea of using volumetric direct solar collectors is raised.

\section{APPLICATIONS OF NANOFLUIDS}

1. Heat Transfer: The mixture of ethylene glycol and water is almost a universally used vehicle coolant due to its lowered freezing point as well as its elevated boiling point. The thermal conductivity of ethylene glycol is relatively low as compared to that of water, while the engine oils are much worse heat transfer fluids than ethylene glycol in thermal conduction performance.

2. Electronics Cooling: The heat dissipated in IC (integrated circuits) and microelectronic components has usually increased due to their size reduction. Better heat transfer management and cooling fluids with improved thermal transport properties are required for safe operation. Nanofluids have been considered as working substance in heat pipes for electronic cooling application.

3. Military Applications: Military hardware both mechanical and electrical devices dissipates a large amount of heat and consequently requires cooling fluids with high heat flux having sufficient cooling capacity. Nanofluids have the capability to provide the required cooling capacity in such applications, as well as in other military applications, including submarines and high power beam laser.

4. Biological Application: Nanofluids are being developed in the field medical applications, including cancer therapy. Iron based nanoparticles can be used as delivery vehicle for radiation without damaging the adjacent healthy tissues by providing the particles up the blood stream to the tumor locations with magnets. Nanofluids could be used to produce higher temperatures around tumors, to kill cancerous cells without affecting the nearby healthy cells. Nanofluids could also be used for safe surgery by cooling around the surgical region, thereafter enhancing the patient's health and reducing the risk of tissue damage.

\section{CHALLENGES}

The following are the remaining challenges in the field of Nanotechnology:

1. Nanoparticle may form agglomerates and settle rapidly in the nanofluids. It forms a layer on the surface and reduce the overall heat transfer capacity.

2. Due to larger size of nanoparticles or agglomerates may clog the cooling channels.

3. There should be a suitable choice of base fluid and nanoparticle to form a nanofluid for optimum performance in particular application.

4. Heat transfer data are sparse all over. No clear trends for application guidelines.

5. Brownian motion effect is still controversial; it may need to be revisited particularly on the effect of temperature.

6. Life cycle of nanofluid is very less i.e. it may expensive. There should be ability to suspend nanoparticle in basefluids for long period of time.

The below graph give an overview for expenditure of government of USA. Our country also needs some advancement for expenditure in the field of nanotechnology.

Error! Objects cannot be created from editing field codes.

Figure 3 Summary of R\&D for Nanotechnology by U.S. Government

\section{CONCLUSION}

A preparation method of nanofluids has been developed. With this method, several sampled nanofluids have been prepared by directly mixing nanophase powders and base fluids, which reveals the possibility of practical application of the nanofluid. The nanofluid shows great potential in enhancing the heat transfer process. One reason is that the suspended ultrafine particles remarkably increase the thermal conductivity of the nanofluid. The volume fraction, shape, dimensions and properties of the nanoparticles affect the thermal conductivity of nanofluids. The measurement illustrate that the thermal conductivity of nanofluids remarkably increases with the volume fraction of ultrafine particles. With respect to the complicated phenomena of Brownian diffusion, sedimentation, dispersion which may coexist in the main flow of a nanofluid, the dispersion model has 
been used to analyze the enhanced heat transfer mechanism of nanofluid. However, experimental research is urgently required to investigate the heat transfer process of nanofluids. It is also concluded that some financial institutions have to sponsor some funds for more research in the field of nanotechnology for its consideration as developed technology.

\section{ACKNOWLEDGMENT}

The author wants to reveal special thanks to his father for the great support given by him. The gratitude for the technical support given by the co-author and guide and also thankful to the HoD, Principal of the VITEast, Jaipur.

\section{REFERENCES}

[1] Choi, S.U.S. (1995), Development and Applications of NonNewtonian Flows (Ed. D. A. Singiner, H. P. Wang), ASME, New York, USA, pp. 99-106.

[2] Yimin Xuan, Qiang Li (2000), Heat transfer enhancement of nanofluids, International Journal of Heat and Fluid Flow 21, $58 \pm 64$.

[3] Adnan M. Hussein, R. A. Bakar, K. Kadirgama and K. V. Sharma, Heat Transfer Enhancement with Elliptical Tube Under Turbulent Flow Tio2-Water Nanofluid, Al-Haweeja Institute, Foundation of Technical Educations, IRAQ.

[4] Choi, S. U. S., Eastman (1995), J. A., Enhancing Thermal Conductivity of Fluids with Nanoparticles, InternationalMechanical Engineering Congress and Exhibition, San Francisco, Cal., USA.

[5] Heris, S.Z. (2009), Convective Heat Transfer of a Cu/WATER Nanofluid Flowing through a Circular Tube, Experimental Heat Transfer, 22, pp.217-227.

[6] Vikrant Khullar, Himanshu Tyagi (2006), Application of Nanofluids as the Working Fluid in Concentrating Parabolic Solar Collectors, Proceedings of the 37th National \& 4th
International Conference on Fluid Mechanics and Fluid Power, December 16-18, IIT Madras, Chennai, India.

[7] Choi, S. U. S (1995), Enhancing Thermal Conductivity of Fluids with Nanoparticles, ASME FED, 231, 66, pp. 99-103.

[8] Boyle, G., (2004), Renewable Energy Power for a Sustainable Future, Oxford University Press, second edition, pp. 51.

[9] Pak, B.C., Cho, Y.I. (1998), Hydrodynamic and Heat Transfer Study of Dispersed Fluids with Submicron Metallic Oxide Particles, Experimental Heat Transfer, 11, pp.151-171.

[10] Choi, S. U. S. (1999), Nanofluid Technology: Current Status and Future Research, Korea - U. S. Technical Conference on Strategic Technologies, Vienna.

[11] Bianco, V. (2011), Numerical Investigation on Nanofluids Turbulent Convection Heat Transfer Inside a Circular Tube, Int. J. of Thermal Sciences, 50, pp.341-349.

[12] R. Saidur, T.C. Meng, Z. Said, M. Hasanuzzaman, A. Kamyar (2012), Evaluation of the effect of nanofluid-based absorbers on direct solar collector, International Journal of Heat and Mass Transfer, Elsevier.

[13] Brewster, M. Q. (1992), Thermal Radiative Transfer and Properties, Wiley and sons, pp. 221-224, 502, 507, 508.

[14] Choi, S.U.S., (2001), et al., Anomalous Thermal Conductivity Enhancement in Nano Tube Suspensions, Applied physics letters, 79, 14, pp. 2252-2254.

[15] J.A. Eastman, Mechanisms of Enhanced Heat Transfer in Nanofluids, U.S. Department of Energy, Office of Science, Office of Basic Energy Sciences, under contract W-31-109Eng-38.

[16] Shanthi R, Shanmuga Sundaram, Anandan, Velraj (2012), Heat Transfer Enhancement using Nanofluids an Overview, Thermal Science, Vol. 16, No. 2, pp. 423-444.

[17] Manglik, R.M., Bergles, A.E. (1992), Heat transfer and pressure drop correlations for twisted-tape inserts in isothermal tubes: part II-transition and turbulent flows,Enhanced Heat Transfer, Transaction ASME, Journal Heat Transfer, 202, pp. 99-106. 